\title{
Nutritional status of under-five pulmonary tuberculosis patients before and after six-month therapy
}

\author{
Barita Sidabutar, MD; Soepardi Soedibyo, MD; Alan Tumbelaka, MD
}

\begin{abstract}
Background Tuberculosis (TB) is a chronic infectious disease which remains a health problem throughout the world including in Indonesia. The implementation of directly observed treatment shortcourse (DOTS) strategy will hopefully increase patient's compliance, so that a minimum of $85 \%$ cure rate could be achieved. The success in coping with TB disease is expected to become one of factors that play role in providing a solution for malnutrition problems in Indonesia, especially for those caused by TB.

Objective The aim of this study was to determine the distribution of nutritional status of under-five TB patients before and after six month therapy.

Methods We reviewed under-five children with pulmonary TB visiting the Pediatric Pulmonology Outpatients Clinic of Cipto Mangunkusumo Hospital from January 1999 to December 2001.

Results Using the weight-for-age (W/A) indices, from 279 patients, the proportion of well-, under-, and severe-malnourished status was $36.9 \%, 60.2 \%$, and $2.9 \%$, respectively, and after 6 -month therapy it became $58.8 \%, 39.8 \%$, and $1.4 \%$, respectively.

Conclusion After 6 months of therapy, the nutritional status of TB patients increased [Paediatr Indones 2004;44:21-24].
\end{abstract}

Keywords: tuberculosis, nutritional status, anthropometric, under-five children

$\mathrm{P}$ attern of diseases that occurs in developing countries is mostly infectious disease, parasite infestation, and malnutrition. There are four major nutritional deficiency problems in Indonesia i.e., protein-energy malnutrition (PEM), vitamin A deficiency, iron deficiency, and iodine deficiency. ${ }^{1}$ Malnutrition is one of the predisposing factors causing infectious disease. ${ }^{2}$ In developing countries, infectious diseases remain the main cause of morbidity and mortality. Infectious diseases and nutritional status have a reciprocal relation influencing each other, for example, tuberculosis (TB) ${ }^{3}$ Tuberculosis is one of the chronic infectious diseases which remains a health problem throughout the world including in Indonesia. The success in coping with TB disease is expected to become one of factors that play role in providing a solution for malnutrition problems arising in Indonesia, especially for those caused by TB.

The aim of this study was to find out the distribution of under-five TB patients, the frequency of malnutrition, and the distribution of nutritional status after 6 months of antituberculosis drugs (ATD) therapy at the Pediatric Pulmonology Outpatient Clinic of Cipto Mangunkusumo Hospital.

\section{Methods}

This was a descriptive retrospective study. Data were retrieved from medical records of the Pediatric Pulmonology Outpatient Clinic Cipto Mangun-

From the Department of Child Health, Medical School, University of Indonesia /Cipto Mangunkusumo Hospital, Jakarta

Reprint requests to: Barita Sidabutar, MD, Department of Child Health, Medical School, University of Indonesia, Cipto Mangunkusumo Hospital. Tel. 62-21-3907741, Fax. 62-21-3907743. 
kusumo hospital from January 1999 to December 2001.

Criteria of inclusion were new under-five patients diagnosed as having pulmonary $\mathrm{TB}$, who underwent regular ATD treatment, and had finished the sixmonth course of ATD therapy. Criteria of exclusion were patients who continued their treatment outside our clinic, had congenital anomaly or syndrome, had a large mass of tumor, or had other chronic disease that affected the body weight such as asthma. The range of nutritional status used weight-for-age (W/ A) indices i.e., well-nourished (80-120\%), undernourished (60-80\% without edema), and severe malnourished (60-80\% with edema and $<60 \%$ ). Data were processed using SPSS computer program and displayed in text, tables, and figure.

Subjects were classified into three age groups: $0-<1$ year, $1-<3$ year, and 3-5 year-old. Tuberculosis was diagnosed based on the National Consensus and the Indonesian Society of Pediatrician criteria. The ATD therapy consisted of isoniazid (INH), rifampicin (RMP), and pyrazinamide (PZA) during the first two months followed by INH and rifampicin for 4 months. The nutritional status of the patients was evaluated before and after 6 months of therapy.

\section{Results}

\section{Characteristics of tuberculosis patients}

During the period of January 1999 until December 2001, there were 472 children's data collected. We included 279 patients consisting of 147 (52.7\%) male and $132(47.3 \%)$ female. Table 1 shows the subjects' characteristics based on age group and sex. The youngest subject was a three-month-old child.
Table 1. Distribution of TB patients according to AGE AND SEX

\begin{tabular}{lccc}
\hline Age group (year) & male & female & Total \\
\hline $0-<1$ & 26 & 29 & 55 \\
$1-<3$ & 82 & 80 & 162 \\
$3-5$ & 39 & 23 & 62 \\
\hline Total & 147 & 132 & 279 \\
\hline
\end{tabular}

Nutritional status (W/A) before and after 6 months of ATD therapy

Using the W/A indices, before therapy, there were 103 (36.9\%) well-nourished, 168 (60.2\%) undernourished, and $8(2.9 \%)$ severe malnourished subjects. Undernourished status was most frequently found among the $1-<3$ year-old group.

Table 2 shows that after therapy for 6 months, the distribution of nutritional status were 164 (58.8\%) well-nourished, 111 (39.8\%) undernourished, and 4 (1.4\%) severe malnourished.

Nutritional status (W/A) changes before and after 6-month therapy

The changes of nutritional status (W/A) before and after 6-month therapy are shown in Figure 1. One $(0.4 \%)$ well-nourished child changed to overweight. Sixty-seven $(24.0 \%)$ undernourished children changed to well-nourished, 4 (1.4\%) severe malnourished children to undernourished. Two hundred and two (72.4\%) subjects stayed in their former nutritional status: 97 children (34.8\%) were well-nourished, 101 (36.2\%) undernourished, and 4 $(1.4 \%)$ severe malnourished. Six well-nourished children became undernourished $(2.2 \%)$

The most frequent change of nutritional status was from undernourished to well-nourished, which occurred in $13(4.7 \%)$ children at the age of $0-<1$ years, $38(3.6 \%)$ children at the age of $1-<3$ years, and $16(5.7 \%)$ children at the age of $3-<5$ years.

Table 2. Distribution of nutritional status (W/A) of TB patients before and after 6MONTH THERAPY.

\begin{tabular}{|c|c|c|c|c|c|c|}
\hline \multirow[t]{2}{*}{ Category } & \multicolumn{2}{|c|}{ Before therapy } & \multirow{2}{*}{$\begin{array}{l}\text { Total } \\
\mathrm{n}(\%) \\
\end{array}$} & \multicolumn{2}{|c|}{ After therapy } & \multirow{2}{*}{\begin{tabular}{|l|} 
Total \\
$\mathrm{n}(\%)$
\end{tabular}} \\
\hline & Male & Female & & Male & Female & \\
\hline Well-nourished & $56(29.1)$ & $47(16.8)$ & $103(36.9)$ & $94(33.7)$ & $70(25.1)$ & $164(58.8)$ \\
\hline Undernourished & 90 (32.2) & $78(28.0)$ & $168(60.2)$ & $52(18.6)$ & $59(21.1)$ & $111(39.8)$ \\
\hline Severe malnourished & $1(0.4)$ & $7(2.5)$ & $8(2.9)$ & $1(0.4)$ & $3(1.0)$ & $4(1.4)$ \\
\hline Total & $147(52.7)$ & $132(47.3)$ & $279(100.0)$ & $147(52.7)$ & $132(47.3)$ & $279(100.0)$ \\
\hline
\end{tabular}




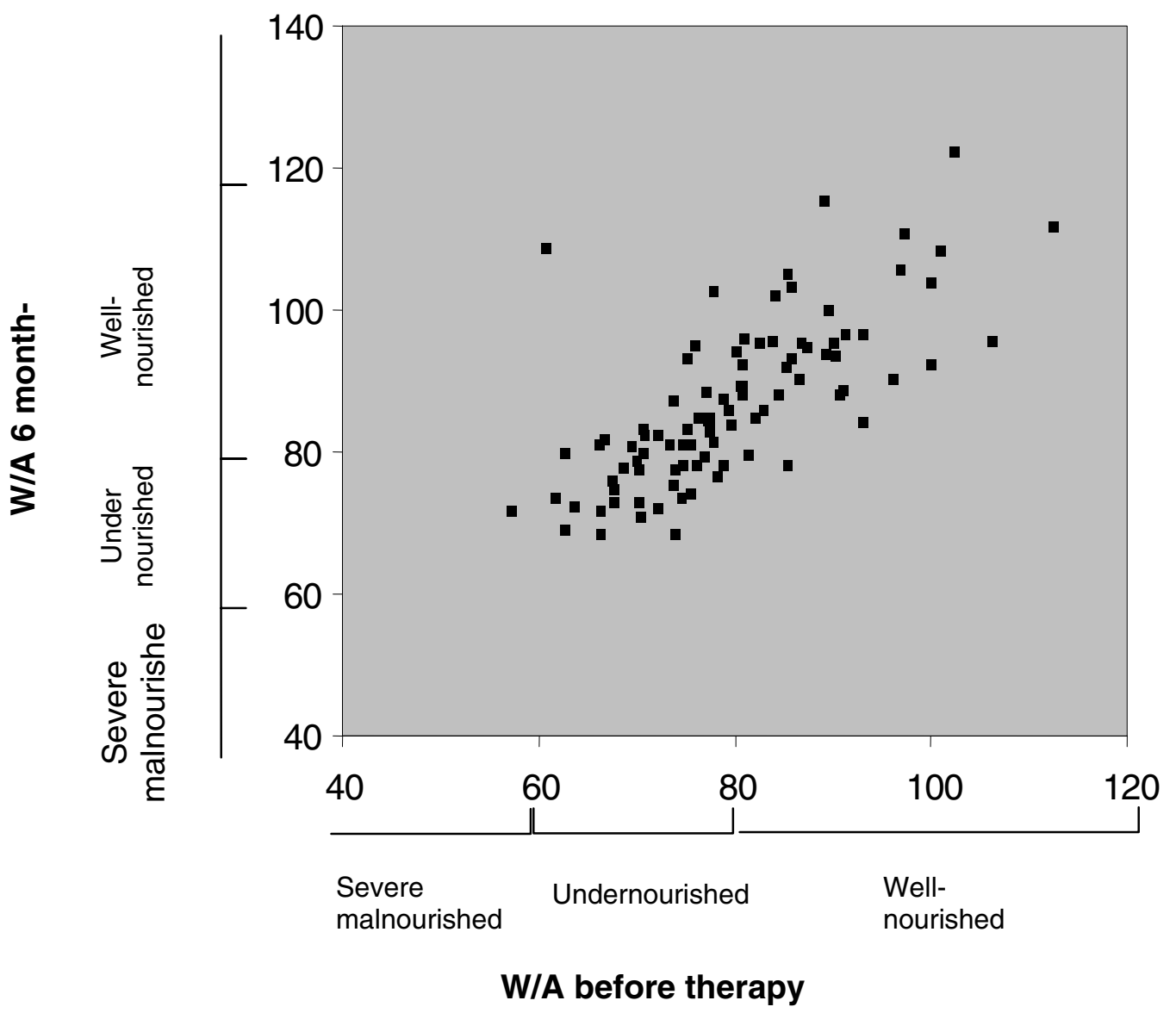

Figure 1. Nutritional status changes (W/A) before and after therapy

\section{Discussion}

During the period of 3 years (January 1999 until December 2001), 279 of 472 under-five-year TB patients who visited the Pulmonology Outpatient Clinic of Cipto Mangunkusumo Hospital met the study criteria, consisting of $147(52.7 \%)$ male and 132 (47.3\%) female, giving an average of 93 patients per year. The number of drop out in this study equalled to $18.6 \%$ of 472 children. With a new strategy recommended by the Ministry of Health and the DOTS strategy, it is expected that the recovery rate will exceed $85 \%$ and the drop out rate will be less than $5 \% .{ }^{4}$ The data of this study indicated a drop out rate which remained high in patients treated until 6 months. This study did not evaluate recovery rate since many patients receiving 6-month therapy were excluded from the study because of the existence of other diseases and no data of body height.
Maltezou et $a^{5}$ found TB in 21 (54\%) male and $18(46 \%)$ female infants. Al-Mari ${ }^{6}$ reported a comparative study of under-five boys and girls suffering from TB as many as 24 and 26 children respectively, while in this research 147 (52.7\%) boys and 132 (47.3\%) girls were found. Even though there are differences in these studies, apparently the proportion of boys and girls almost equals statistically.

Literature said that age of under-five years is a high risk factor for TB. ${ }^{7}$ We found that TB most frequently occurred in the $1-<3$ year-age group $(57.8 \%$ subjects) followed by the $3-<5$ year-age group $(22.2 \%)$ and the $0-<1$ year-age group (19.7\%). No data could explain why tuberculosis most frequently occurred in the age of $1-<3$ years. It is probably because at those ages, children have not gone to school yet, so they spend most of the time at home where the possibility of having close contact with adult TB patients is more likely to occur. 
We found that most $(60.2 \%)$ of the TB patients were undernourished, i.e., 168 out of 279 . Out of the 168 undernourished subjects, 103 (61.3\%) were 1-3 years old.

Our study could not discern whether the malnutrition occurred before or after the subjects suffered from TB. The Global Burden Disease study in 1992 reported that the risk of the length of malnutrition towards TB disease was $16 \%$, while poor sanitation and hygiene was $7 \% .{ }^{8}$ Schaff et al reported a decrease of body weight in $48 \%$ of 109 children with confirmed TB and $53 \%$ of 86 children with suspected TB. ${ }^{9}$ The pathogenesis of malnutrition occurs through insufficient food intake and metabolism change. ${ }^{10}$ Malnutrition in TB disease is caused indirectly through anorexia, cough, and fever which result in insufficient food intake and change in metabolism.

Our study found that the number of well-nourished TB patients increased from 103 to 164 children and the number of severe malnourished decreased from 8 to 4 children, while the number of undernourished decreased from 168 to 111 . The success of therapy is only one of many factors contributing to nutritional status. The fulfilment of nutritional intake is also important to change nutritional status.

Most of the patients [67 (24.0\%)] gained weight after 6 months of ATD treatment, but there were 6 patients who lost weight. There were 4 severe malnourished children who did not undergo change in nutritional status after therapy and they experienced failure to thrive or marasmus. Besides infection, there are several factors that influence the nutritional status, such as less intake, congenital malformation, psychological condition, etc. A special management needs to be carried to raise the nutritional status of the children.

In this study, to assess the nutritional status after 6-month therapy, we only used W/A indices because no data of body height were found. Actually, it would be better to use weight-for-height $(\mathrm{W} / \mathrm{H})$ indices ${ }^{11}$ because W/A indices is more appropriate to assess acute cases.

Many medical and non-medical factors influence the study results. Non- medical factors were, among other things, methods of measurement, patient's attitude in receiving treatment, economy, etc., whereas medical factor was, among other things, drug resistance problem. Good education is needed for TB pa- tients and their parents with consideration to nonmedical and medical aspects, so that in the future a maximum result can be expected.

We concluded that most TB patients were in the 1-3 year-age group, followed by the 3-5 year-age group. Most subjects were undernourished, especially in the age group of 1-3 years. After 6 months of therapy, undernourished status decreased and wellnourished status increased. To gain a better result, an analytical prospective study using larger samples control group is needed; all subjects need to be measured for body weight and height.

\section{References}

1. Markum AH. Wawasan dan lingkup ilmu kesehatan anak. In: Markum AH, Ismael S, Alatas H, Akib A, Firmansyah A, Sastroasmoro S, editors. Buku Ajar Ilmu Kesehatan Anak. Jakarta: BP FKUI; 1991. p. 1-8.

2. World Health Organization. Update on the nutrition situation. Geneva: ACC/SSCN; 1989. p. 1-9.

3. Latham MC. Nutrition and infection in national development. Science 1975;188:561-5.

4. Depkes RI. Pedoman nasional penanggulangan tuberkulosis. 6th ed. Jakarta: Depkes RI; 2001. p. 11-22.

5. Maltezou HC, Spyridis P, Kafetzis DA. Tuberculosis during infancy. Int J Tuberc Lung Dis 2000;4:414-5.

6. Al-Mari. Childhood tuberculosis in the state of Qatar: the effect of a limited expatriate screening programme on the incidence of tuberculosis. Int J Tuberc Lung Dis 2001;5:831-7.

7. Houwert KA, Borggreven PA, Schaff HS, Nel E, Donald PR, Stolk J. Prospective evaluation of World Health Organization criteria to assist diagnosis of tuberculosis in children. Eur Respir J 1998;11:1116-20.

8. Murray CJ, Lopez AD. Global mortality, disability, and contribution of risk factors. Global Burden of Disease Study. Lancet 1997;349:1436-42.

9. Schaff HS, Beyers N, Gie RP, Nel ED, Smuts NA, Scott FE. Respiratory tuberculosis in childhood: the diagnosis value of clinical features and special investigations. Pediatr Infect Dis J 1995;14:189-94.

10. Tomkins A, Watson F. Malnutrition and infection: a review. London: WHO ACC/SCN; 1989. p. 1-44.

11. Nasar SS. Pengkajian status nutrisi anak di klinik. Presented at the $10^{\text {th }}$ National Congress of Pediatric; 1996 June 16-20; Bukittinggi, Indonesia. 